Japan. J. Med. Sci. Biol., 27, 263-268, 1974

\title{
TWO MODES OF MORPHOLOGICAL CHANGES OF CYST FOUND \\ IN THE BRAIN OF MICE CHRONICALLY INFECTED WITH BEVERLEY STRAIN OF TOXOPLASMA GONDII
}

\author{
ICHIRO NAKAYAMA \\ Department of Parasitology, School of Medicine, Keio University, \\ Shinjuku-ku, Tokyo 160, Japan \\ (Received: May 16, 1974)
}

\begin{abstract}
SUMMARY : Two modes of morphological changes of cyst, rupture and budding-like protrusion, were observed in emulsions and microscopic sections of the brain of the mice infected chronically with Beverley strain of Toxoplasma gondii. These changes seem to be related to the formation and the growth of the cyst, and tended to appear more often in the mice injected with cortisone than in those not injected.
\end{abstract}

\section{INTRODUCTION}

No report has been published on rupture or budding-like protrusion of Toxoplasma gondii cysts in vivo, although some investigators found such phenomena. Such changes suggestive of rupture and protrusion were observed in the same material in the present study and described for the first time. The effect of cortisone on the morphological changes of cysts was also investigated.

\section{MATERIALS AND METHODS}

Animals: The animals used were ICR mice of both sexes weighing approx. $20 \mathrm{~g}$ at the start of the experiment.

Parasites: The Beverley strain of Toxoplasma gondii was used through out the present study.

Schedule for observation: (1) About 1,000 trophozoites harvested by Nakayama's method (Nakayama, 1967) were inoculated intraperitoneally into each mouse. (2) Cortisone (cortisone acetate, Merck \& Co., Rahway, New Jersey, U.S. A.) was injected subcutaneously in dosage of $0.25 \mathrm{mg}$ in $0.1 \mathrm{ml}$ of saline solution to each chronically infected mouse every other day for 5 weeks, starting 80 days after the infection with Toxoplasma gondii. (3) The forms of cysts in brain homogenate of both the cortisone-treated and the untreated mice were observed from 115 days after the infection, and the unmber of cysts and the percentage of the cyst showing morphological changes were also calculated. (4) In another group of mice, which were

中山一郎（慶応義塾大学医学部 寄生虫学教室 新宿区信濃町 35）

Present address: Department of Parasitology, School of Medicine, Tokai University, Boseidai, Isehara-shi, Kanagawa 259-11, Japan. 
infected with the parasites and treated with cortisone in the way mentioned above for 35 days starting 40 days after infection, cysts were also calculated. (5) Simultaneously, histological sections were made of the brains of the infected mice and stained with hematoxylin-eosin (HE). To stain the cyst wall, p-aminosalicylic acid (PAS) and Luxol fast blue (LFB) were also used.

\section{RESULTS}

In brain emulsion of both the mice treated and untreated with cortisone, cysts showing budding-like protrusion were found (Fig. 1).

The appearance of such protruding cyst, however, seemed to be more often in cortisone-treated mice than in untreated mice as shown in Table I. Moreover, the mean number of cysts detected in the former was more than three times as large as that of the latter, although a variation in the cyst number was recognized among the infected mice (Table II).

Other morphological changes on cysts were also found in such brain emulsion, e.g., the cyst with a space between the cyst wall and the cluster of zoites* (Fig. 2), that packed fully with moving zoites (Fig. 3), that packed loosely with moving zoites (Fig. 4), etc.

\section{TABLE I}

Protruding cysts found in brain emulsion of mice infected chronically with Beverley strain of Toxoplasma gondii; comparison between mice treated with cortisone and those untreated

\begin{tabular}{cccccc}
\hline \multirow{2}{*}{$\begin{array}{c}\text { Mice } \\
\text { examined }\end{array}$} & $\begin{array}{c}\text { Cortisone } \\
\text { treatment }\end{array}$ & $\begin{array}{c}\text { Cysts } \\
\text { examined }\end{array}$ & \multicolumn{2}{c}{ Protruding cysts } \\
\cline { 5 - 6 } & + & 1201 & No. & $\%$ \\
\hline 19 & - & 705 & 15 & 2.1 \\
22 & & &
\end{tabular}

Cortisone was given every other day for 5 weeks, starting 80 days after the infection.

TABLE II

Mean number of cysts found in the brain of mice infected chronically with Beverley strain of Toxoplasma gondii; comparison between mice treated with cortisone and those untreated

\begin{tabular}{ccc}
\hline $\begin{array}{c}\text { Mice } \\
\text { examined }\end{array}$ & $\begin{array}{c}\text { Cortisone } \\
\text { treatment }\end{array}$ & $\begin{array}{c}\text { Mean number of cysts } \\
\text { per mouse }\end{array}$ \\
\hline 6 & + & $4,337(1,680-14,340)$ \\
5 & - & $1,200(40-3,960)$ \\
\hline
\end{tabular}

Cortisone was given every other day for 5 weeks, starting 40 days after the infection.

* Zoites mean the organisms asexually propagated inside the cyst (WHO Tech. Rep. Ser., $431,30,1969)$. 


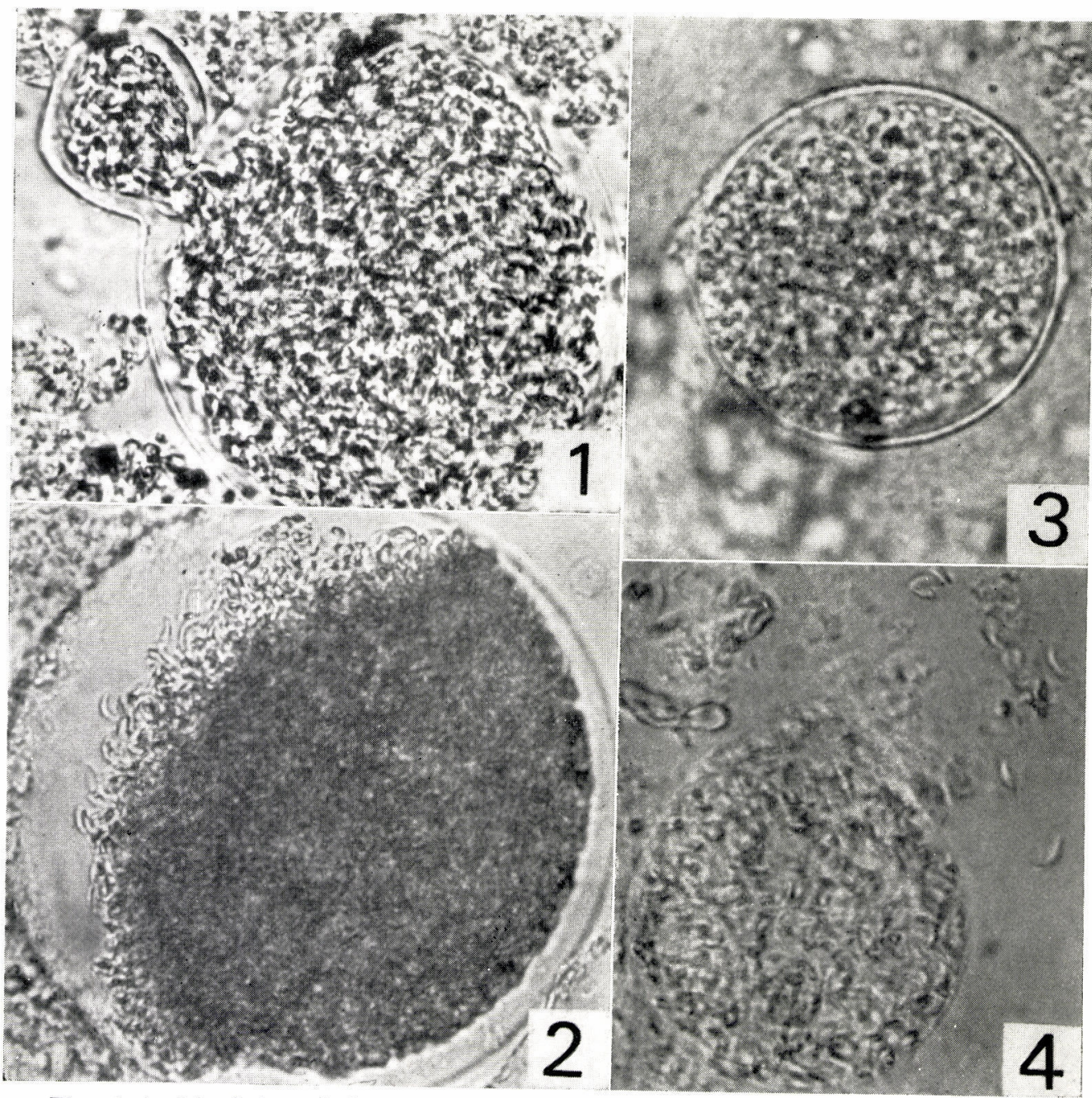

Figs. 1-4. Morphological changes of cysts found in brain homogenate obtained from mice infected chronically with Toxoplasma gondii. (1200×)

Fig. 1. A cyst showing protrusion with a narrow neck connecting two parts of a cluster.

Fig. 2. Many zoites released from a cluster in a cyst.

Fig. 3. A cyst filled up with many moving zoites.

Fig. 4. Free zoites and a cyst filled loosely with moving zoites.

In sections of the infected mouse brain, the rupturing cyst and the zoites being liberated from such a cyst accompanied by host cell infiltration in the adjacent tissues were sometimes observed (Fig. 5). Such host cell infiltration was found only in the case of rupture of a cyst. Cysts showing budding-like protrusion were also detected, showing depressions at both sides of the cluster of zoites (Fig. 6). Even in sections, these morphological changes were found in the brains of mice treated with cortisone and untreated ones as well.

Throughout the experiment, HE, PAS and LFB failed to stain the cyst wall. 


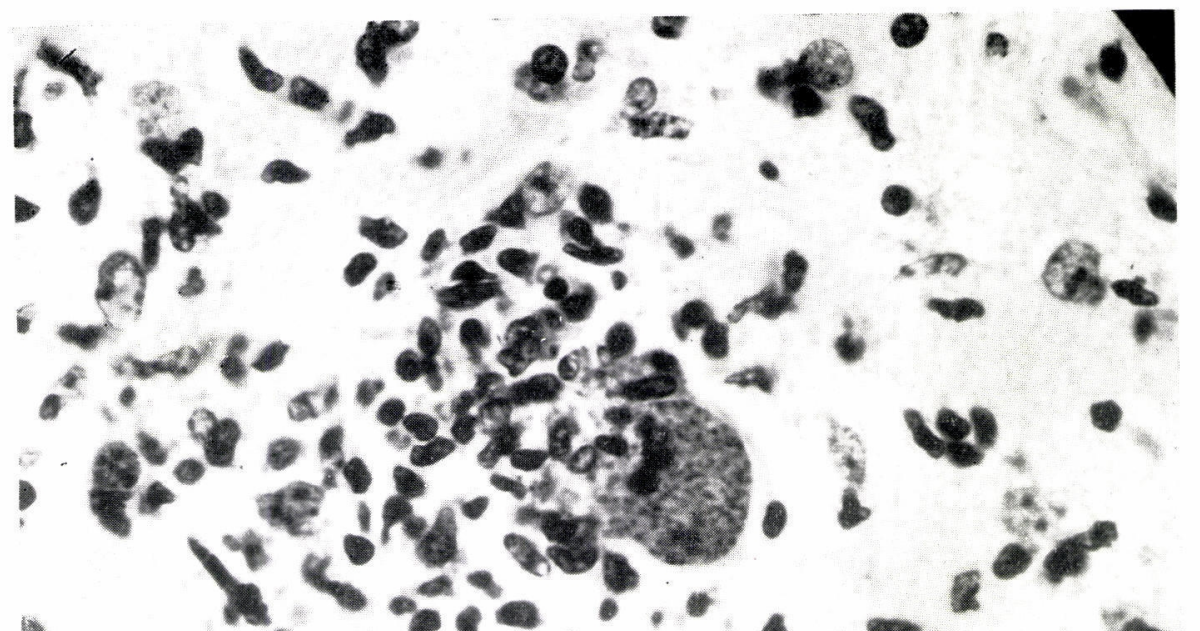

(s)

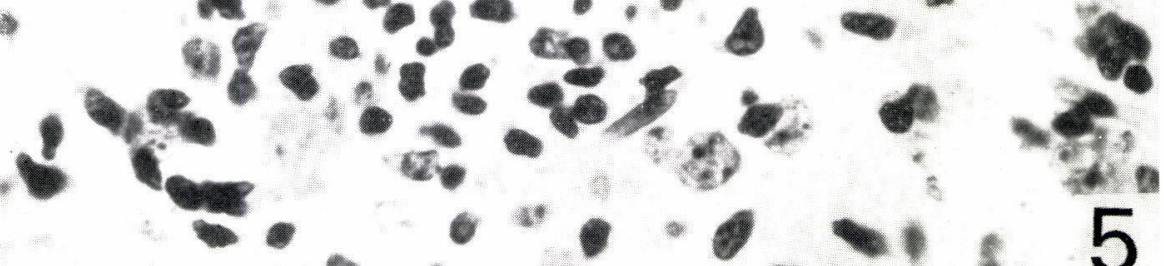
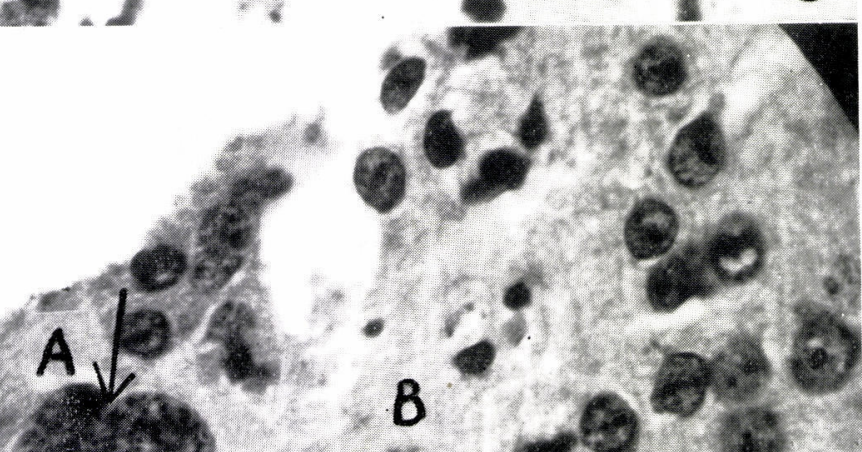

a. $\quad 0+15$

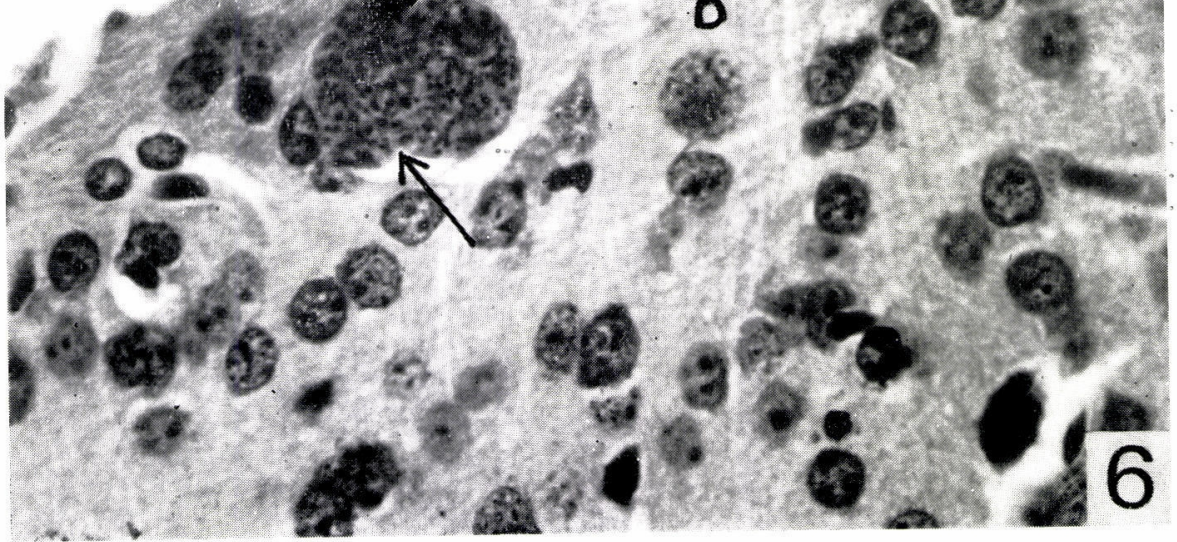


Figs. 5-6. The two modes of morphological changes of cysts in the histological section of the brain of a mouse infected chronically with Toxoplasma gondii. (840X)

Fig. 5. A rupturing cyst with zoites liberated in the host tissue and host cell infiltration around it.

Fig. 6. Protruding (A) and normal (B) cysts. Arrows indicate the neck of a cyst formed by a protruding part of the body. No pathological finding is seen around either cyst.

\section{Discussion}

It has been suggested that the secondary or the successive cysts may originate from the primary cysts produced in the tissues of the host after the infection with Toxoplasma gondii, but no definite evidence has yet been obtained.

In the present study, two kinds of morphological changes of the cyst, rupture and budding-like protrusion, were first observed in saline homogenate as well as in sections of the brain obtained from mice chronically infected with Beverley strain of Toxoplasma gondii. These phenomena are strongly suggestive of development and increase in number of cysts in host tissues, namely dispersion of zoites and formation of new cysts in the brain tissues might result from rupture of the cyst or separation of the bud from the budding cyst.

Special regard must be paid to a mechanical action which may exert some influences upon the cysts in the course of triturating the brains. But both morphological changes may possibly appear not due to such an action because the changes are often found also in brain sections made carefully.

The relationship between such morphological changes in cysts as rupture and budding and cyst formation may be clarified by investigating development of a single cyst by in vitro cultivation in a favorable medium, though it has been very difficult to cultivate cysts in vitro. The solution is left for future development of culture techniques.

Microscopic examinations of histological sections revealed cellular infiltration in the host tissues adjacent to the rupturing cyst accompanied by some liberated zoites, but such pathological changes were never seen around the normal cyst or the budding cyst. These findings were considered to be immunologically very interesting.

The influence of cortisone on acute and chronic toxoplasmosis has been investigated experimentally by many workers (Jacobs and Melton, 1953; Frenkel, 1956, 1957, 1960, 1967; Frenkel and Lunde, 1966; Nakayama, 1973), but its mechanism on the disease has never been elucidated. In experimental acute toxoplasmosis caused by injecting with trophozoites of Beverley or RH strain, Nakayama and Aoki (1972) observed that the cortisone-treated mice had much heavier propagation of trophozoites in the abdominal cavities than in nontreated mice.

As a result of the present study it was considered that cortisone may also play a role in increasing the number of both normal cysts and the cysts showing morphological changes. Cortisone is presumed to have an ability to stabilize lysosomal membranes, and it is therefore suggested that the exudation of lysosomal enzymes and the subsequent intracellular digestion may be inhibited by the cortisone treatment, and that the toxoplasmas having invaded the host cells may develop without any difficulty (Honma, personal communication). Moreover, it is postulated that cortisone may dissolve the lymphocytes which produce cellular immunities (Honma, Ichikawa 
and Nishiumi, 1972). Further investigations on the morphological changes of the cysts with due consideration of these hypotheses are required to elucidate the significance of such phenomena as rupture and budding of cysts and the role of cortisone on the mechanism.

\section{ACKNOWLEDGEMENT}

The author is indebted to Dr. Kenya Horie, Cheif of Department of Pathology, Tachikawa Hospital, Federation of Mutual Aid Association, and his team for their skillful histological techniques and for their valuable discussions.

Note added in proof : Recently bradyzoite or cystozoite has been used in place of zoites as a new technical term meaning slowly reproducing parasites (by endodyogeny) within a cyst wall of Toxoplasma gondii. (Jacobs, L.: New knowledge of Toxoplasma and toxoplasmosis. Advances in Parasitology, Vol. 11, 637, 1973, Academic Press, London and New York).

\section{REFERENCES}

FRENKEL, J. K. (1956): Pathogenesis of toxoplasmosis and of infections with organisms resembling Toxoplasma. Ann. N. Y. Acad. Sci., 64, 215-251.

FRENKEL, J. K. (1957): Effects of cortisone, total body irradiation and nitrogen mustard on chronic latent toxoplasmosis. Am. J. Pathol., 33, 618-619.

FRENKEL, J. K. (1960): Pathogenesis of infections of the adrenal gland leading to Addison's disease in man; the role of corticosteroids in adrenal and generalized infection. Ann. N. Y. Acad. Sci., 84, 393-439.

FRENKEL, J. K. AND LUNDE, N. (1966): Effects of corticosteroids on antibody and immunity in Besnoitia infection of hamsters. J. Infect. Dis., 116, 414-424.

FRENKEL, J. K. (1967): Adoptive immunity to intracellular infection. J. Immunol., 98, 1309-1319.

Honma, M., IchiKawa, Y. AND Nishiumi, M. (1972): Collagene disease; mainly the effects of corticosteroids. J. Therap., 54, 563-570 (text in Japanese).

Jacobs, L. AND MELTON, M. L. (1953): The effect of cortisone in murine toxoplasmosis. J. Parasitol., Suppl., 39, 12.

NAKAYAMA, I. (1967): A method of detection of Toxoplasma infection in man. Jap. J. Parasitol., 16, 381-388.

NAKAYAMA, I. AND AOKI, T. (1972): Influence of cortisone on the treatment of acute toxoplasmosis in mice. Jap. J. Parasitol., 21, 109-117 (text in Japanese).

NAKAYAMA, I. (1973): On the treatment of chronic toxoplasmosis in mice, with special reference to the influence of cortisone injection. Jap. J. Parasitol., 22, 354-361 (text in Japanese). 